九州大学学術情報リポジトリ

Kyushu University Institutional Repository

\title{
Development of Design Theory on the Tooth Arrangement and the threshing Drum for a Large- Sized and High-Speed Head-Feeding Combine
}

Choe, Jung Seob

Assistant Professor, Department of Machinery Engineering, Sang Ju National University

Inoue, $\mathrm{Ei} \mathrm{j} \mathrm{i}$

Laboratory of Agricultural Machinery, Faculty of Agriculture, Kyushu University

Hashiguchi, Koichi

Laboratory of Agricultural Machinery, Faculty of Agriculture, Kyushu University

https://doi.org/10.5109/24340

出版情報 : 九州大学大学院農学研究院紀要. 44 (3/4)，pp. 377-384，2000-02. Kyushu University バージョン：

権利関係 : 


\title{
Development of Design Theory on the Tooth Arrangement and the threshing Drum for a Large-Sized and High-Speed Head-Feeding Combine
}

\author{
Jung Seob Choe*, Eiji Inoue and Koichi Hashiguchi \\ Laboratory of Agricultural Machinery, Faculty of Agriculture, Kyushu University, \\ Hakozaki, Higashi-ku, Fukuoka 812-8581, Japan \\ (Receved October 13,1999 and accepted Novermber 5, 1999)
}

\begin{abstract}
This study was intended to develop the design theory of the threshing unit for a largesized and a high-speed head-feeding combine. It may be applied for various combining capacilies with different, cutting widths and forward speeds.

Design factors in the theoretical development are: (1) dimensions of the threshing drum, (2) tooth approaching angle, (3) distance between the adjacent teeth on their spiral setting line, (4) number of spirals, and (5) Lotal number of teeth on the drum.

A computer simulation program was developed to predict the proper dimensions for the threshing drum and tooth arrangement. A simulation for the prospective combine with varied capacities was also demonstrated. The parameters analyzed in the developed design theory were shown to be consistent. with those of existing combines.
\end{abstract}

\section{INTRODUCTION}

A head-feeding combine is widely used in Japan and Korea as a grain harvester. In these days, there is a tendency that the combines have been changing into the wider cutting width and faster forward speed, to give a higher capacity. The threshing part of combines is the kernel part which consumes about one half the total combine energy and has a great influence to the performance of threshing, separation, chafiing, and grain loss (Carrol, T,. 1961). Because of its complexity of threshing phenomenon, the design of the threshing unit has been much dependent upon an experience rather than design theory (Ezaki, H, 1972). However, the trend of high-capacity combines currently demanded requires appropriate justified design theory, This study was intended to develop a theoretical design method for the threshing unit of a head-feeding rice combine.

\section{Derivation of the theoretical Equation about Tooth Arrangement}

The dimension of threshing drum can be defined by its diameter and length. A figure of the developd drum is shown in Fig. 1. Threshing teeth are fixed to the drum, which are made of steel-wire in the shape of the inverted $\mathrm{V}$ or L letters. The tooth has a different shape, generally a lower and wider in the first part and higher and narrow in the last part. The teeth are arranged with spiral form and defined by approaching angle of arrangement-line, distance between teeth, which adjoin on the arrangement-line, and the interval with arrangement-line in the direction of circumference (C. J. Chung, etc., 1972).

\footnotetext{
* Assistant Professor, Department of Machinery Engineering, Sang . In National University, Korca
} 


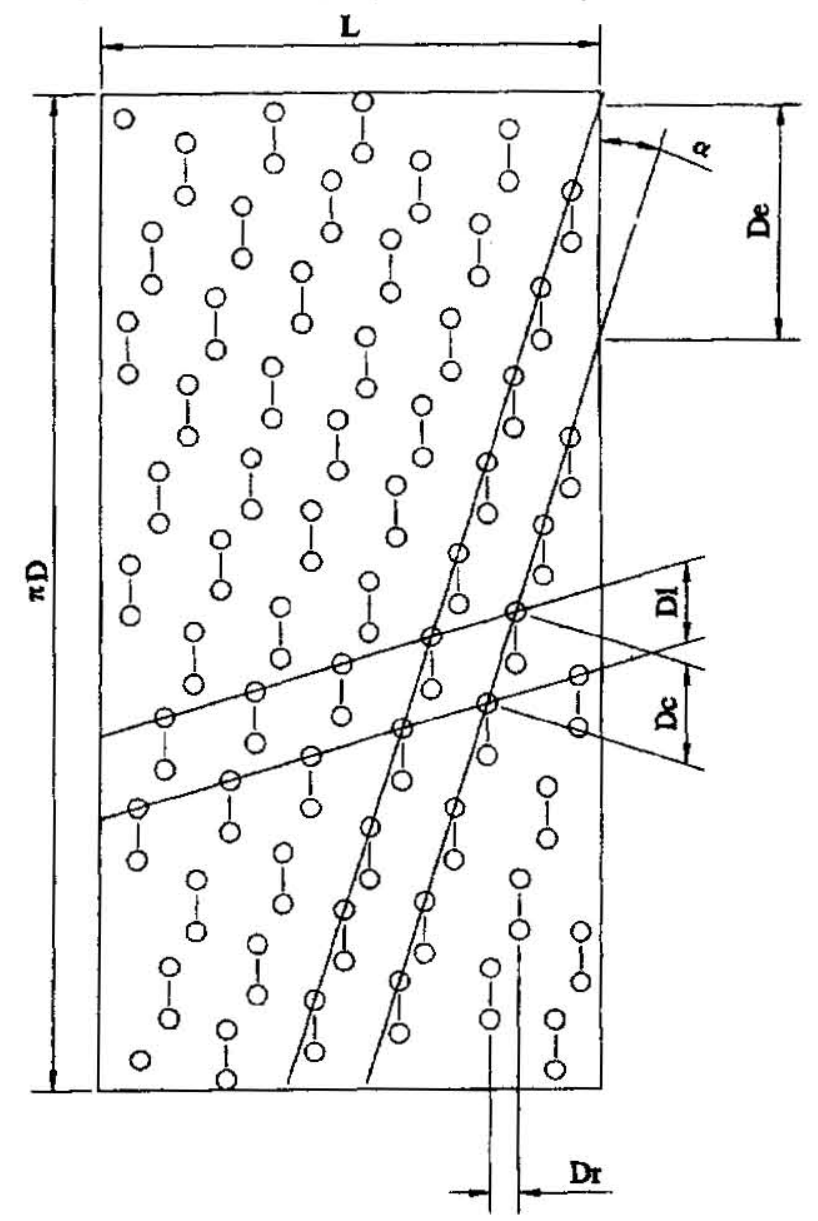

Fig. 1. Variable specification of threshing teeth arrangement

It is necessary to find an analytical relation among them, because these factors are all related with the threshing performance (C. J. Chung, etc., 1985; Quick, G. R., 1972).

\section{Thickness of stems which pass the feeding chain}

Let us denote the forward working speed as $V_{c}(\mathrm{~cm})$, number of rows cut by the cutter $N_{t}$, the interval between each plant bush row $D_{n}(\mathrm{~cm})$, cutting cross sectional area of each bush $A_{r}\left(\mathrm{~cm}^{2}\right)$. The cutting cross sectional area of stems per unit time can be 
expressed as $\left(\frac{V_{t}}{D_{i}}\right) N_{\mathrm{r}} A_{t}$. If we denote the feed chain speed as $V_{t}$, thickness of crops, which pass the feed chain without compression $D_{b}$, the crop's cross sectional area per unit time, which feed into the threshing unit by the feed chain, is $V_{i} D_{t}$. Above two values have to be the same. Therefore,

$$
D_{: 1}=\frac{V_{i} N_{r} A_{r}}{D_{a} V_{i}}
$$

\section{Flail number of tooth}

Suppose that threshing actions may occur by impact of threshing teeth to the crop head. The flail number, as the crops move as much as a unit length $(1 \mathrm{~cm})$ in the direction of axle of drum, are proportional to the total number of triangular tecth and the rpm of drum. Therefore, flail number of teeth per unit width to crops, which move through feed chain, is given as

$$
\begin{aligned}
N_{i} & =N_{i}\left(N_{1}-3\right)\left(\frac{R}{60}\right)\left(\frac{1}{V_{i}}\right) \\
& =\frac{R N_{i}\left(N_{i}-3\right)}{60 V_{i}}
\end{aligned}
$$

Where, $N_{1}=$ Number of teeth arrangement line

$N_{t}=$ Number of teeth included in one arrangement line

$R=$ Rotational speed of drum, rpm

Number of teeth on one arrangement line is equal to the length of arrangement line divided by length between teeth measured in the direction of the line, or

$$
\begin{aligned}
N_{i} & =\frac{L \sec \left(90^{\circ}-\alpha\right)}{D_{r} \sec \left(90^{\circ}-\alpha\right)}=\frac{L}{D_{r}} \\
& =\frac{L}{D_{l} \tan \alpha}
\end{aligned}
$$

Where, $L=$ Length of drum $(\mathrm{cm})$

$D_{1}=$ Lateral distance between adjacent teeth in the arrangement line $(\mathrm{cm})$

$\alpha=$ Approaching angle of arrangement line (deg.)

$D_{i}=$ Interval of flail-line, which is the length of adjacent teeth in the direction of drum circumference.

\section{Relation of feed chain speed to approach speed of arrangement-line}

The approaching speed of the arrangement line to the crops threshed must be equal to the rotational speed of drum multiplied by approaching distance of arrangement line. Therefore, the speed ratio of feed chain to approach of arrangement line is given as 


$$
R,=\frac{\pi D R \tan \alpha}{60 V_{l}}
$$

Where, $D=$ the effective diameter of drum $(\mathrm{cm})$.

\section{Theoretical equation of drum and tooth arrangement}

Based on the above equation developed, it can be derived the dimension of the drum and design equation about threshing tooth. Giving feed chain speed $V$ as in Equation (1), the approach angle of tooth arrangement line, $\alpha$, is given as

$$
\alpha=\tan ^{-1} \frac{60 R_{r} V_{t} N_{r} A_{c}}{\pi R D D_{u} D_{b}}
$$

If the Equation (2) rewrite about $N$, and it is equated with Equation (3), then the length of drum $L$ is given as,

$$
L=D_{i} \tan \alpha\left(\frac{60 V_{i} N_{i}}{R N_{i}}+3\right)
$$

Substituting $V$, of Equation (1) in Equation(6), the length of drum is

$$
L=D_{i} \tan \alpha\left(\frac{60 V_{c} N_{c} A_{r} N_{i}}{D_{a} D_{b} R N_{i}}+3\right)
$$

The length between adjacent two teeth in the direction of arrangement line is given,

$$
D_{\mathrm{c}}=\frac{D_{i}}{\cos \alpha}
$$

The interval of arrangement-lines in the direction of drum's circumference, $D_{\psi}$, is the same value as the drum's circumference divided by the number of arrangernent-line.

$$
D_{i}=\frac{\pi D}{N_{i}}
$$

\section{ANALYSIS ON THE DRUM AND TOOTH ARRANGEMENT}

In deriving the theoretical design equations of threshing drum and teeth arrangement, it was used many design factors and derived variables. To make use of the developed equation in design application, it is need to specify appropriate range of the design factors involved. For instance, Table 1 is a summary of actual values of the design factors measured for head-feeding rice combines having 2-, 3-, 4-rows of cutting width. Fig. 2 shows the developed figure of the threshing teeth arrangement of a 4-row combine.

There are many kinds of teeth as shown in Fig. 2. The teeth may be classified in low-triangular tooth (1), semi-circular tooth (2), double semi-circular tooth (3), low double triangular tooth (4), high double triangular tooth (5), triangular tooth(6), sorting plate (7). Dimensions characterizing the tooth shape are shown in Table 1. 


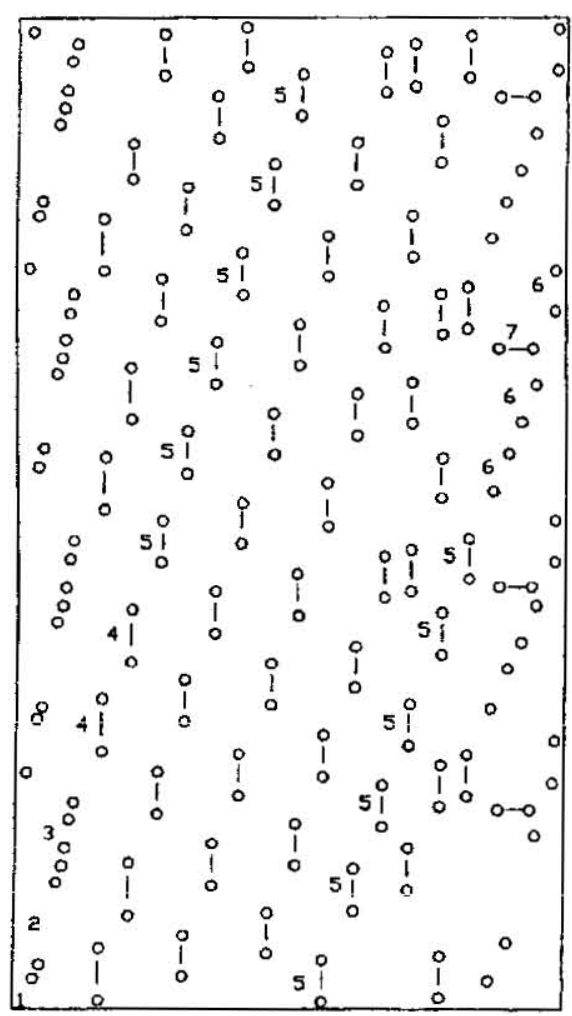

1

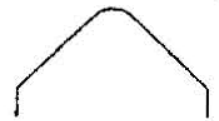

5

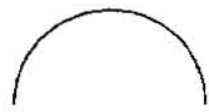

3

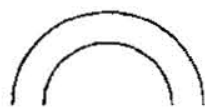

4

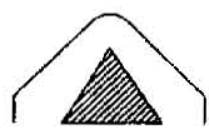

5

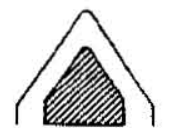

6

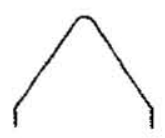

7

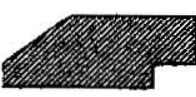

Fig. 2. Threshing teeth arrangement of 4-row head-feeding combine

\section{DESIGN SIMULATION OF THRESHING DRUM AND THRESHING TEETH}

\section{Design for large-sized combine}

It is attempted to design the threshing drum and teeth arrangement for a large-sized head-feeding combine by computer simulation using the design equations already developed and the analyzed variables of the threshing unit of the existing combine. With this method, the threshing unit for varied design factors can be easily designed. The values of variables, which were applied to illustrate the design simulation, are shown in Table 2. Fig. 3 shows the design simulation results for 4-, 6-, and 8-row head-feeding combines.

\section{Design of small combine with a high speed}

Existing 2- or 3-row self-feed combine was designed based of low forward speed (actually lower than $0.6 \mathrm{~m} / \mathrm{s}$ ). The design could be modified to catch up the trend of high 
Table 1. Specification of threshing drum and teeth of the head-fecding combine

\begin{tabular}{|c|c|c|c|c|}
\hline \multicolumn{2}{|c|}{ Sizc of combine } & $2-r(u w$ & 3-row & 4-row \\
\hline & 420 & 420 & 420 \\
\hline \multicolumn{2}{|c|}{ Length of drum (mm) } & 480 & 480 & 750 \\
\hline \multicolumn{2}{|c|}{ Rated rotational speed of drum } & 480 & 480 & 480 \\
\hline \multicolumn{2}{|c|}{ Thickness of drum (mm) } & 5.2 & 5.2 & 6.4 \\
\hline \multicolumn{2}{|c|}{ Height of tooth (mm) } & 68 & 68 & 68 \\
\hline \multirow{2}{*}{\multicolumn{2}{|c|}{$\begin{array}{l}\text { Number of arrangement-line } \\
\text { Number of winding of arrangement-line }\end{array}$}} & 4 & 4 & 4 \\
\hline & & 1.36 & 1.58 & 1.75 \\
\hline \multirow{5}{*}{$\begin{array}{l}\text { Number of tooth } \\
\text { per arrangemen } \\
\text { t-line }\end{array}$} & Low-triangular tooth ${ }^{13}$ & 1 & 1 & 1 \\
\hline & Semi-circular tooth & 1 & 1 & 1 \\
\hline & Double semi-circular tooth & 1 & 1 & 1 \\
\hline & Double triangular tooth & 10 & 12 & 14 \\
\hline & Triangular tooth & 3 & 3 & 3 \\
\hline \multicolumn{2}{|c|}{ Total number of tooth } & 64 & 72 & $84^{2 j}$ \\
\hline \multicolumn{2}{|c|}{ Speed of feed chain $(\mathrm{m} / \mathrm{s})$} & 0.26 & 0.45 & 0.5 \\
\hline \multicolumn{2}{|c|}{ Travel speed of combine $(\mathrm{m} / \mathrm{s})$} & $0.21-1.2(6$ step $)$ & $0.28-1.57$ & $<1.06$ \\
\hline
\end{tabular}

1) The tie-up angles of low-triangular tooth, semi-circular tooth, double semi-circular tooth are $10^{\circ}$, $20^{\circ}, 13^{\circ}$ respectively.

$\Rightarrow$ Add two triangular teeth in each two rows.

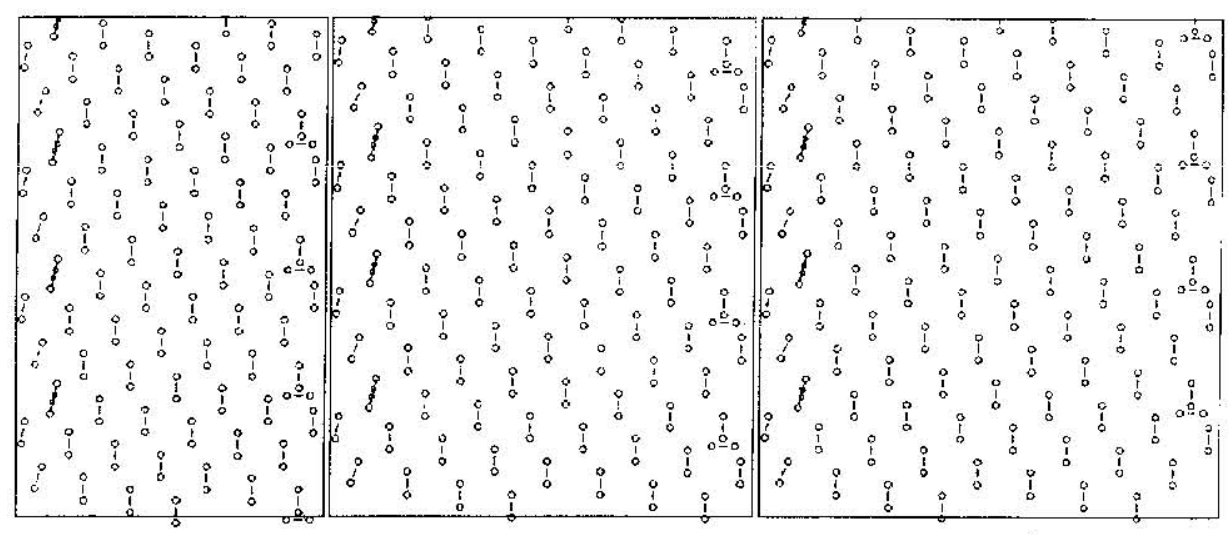

\section{(a)4-row combine $\quad$ (b)6-row combine $\quad$ c)8-row combine}

Fig. 3. Threshing teeth arrangement of large sized combine designed by the design theory developed in this study. 
Table 2. Data used in computer simulation for designs of threshing tecth arranging of the large--sized head-feeding combine.

\begin{tabular}{|c|c|c|c|c|}
\hline Design factor/Kind & & 4-row & 6-row & $8-r o w$ \\
\hline Rotational speed of threshing drum & $R(\mathrm{rpm})$ & & 480 & \\
\hline Diameter of threshing drum & $D(\mathrm{~cm})$ & & 42 & \\
\hline Distance between plant bushes & $D_{1}(\mathrm{~cm})$ & & 15 & \\
\hline Cross-sectional area of each plant bushes & A. $\left(\mathrm{cm}^{2}\right)$ & & $4 \pi$ & \\
\hline Number of arrangement lines & $N_{i}$ & & 4 & \\
\hline Distance between impact lines & D. $(\mathrm{cm})$ & & 12 & \\
\hline Forward speed & $V_{\mathrm{t}}(\mathrm{crm} / \mathrm{s})$ & 100 & 110 & 120 \\
\hline \multicolumn{5}{|c|}{ Ratio of approaching speed of arrangement } \\
\hline line to the speed of feed chain & $R$ & 6.9 & 6.5 & 6.0 \\
\hline Number of impact. & $N$ & 11 & 11 & 11 \\
\hline Thickness of feeding stem & $D_{t}(\mathrm{~cm} / \mathrm{s})$ & 6.7 & 9.0 & 12.0 \\
\hline
\end{tabular}

Table 3. Variables in the simulation of throshing unit design for highter forward specd.

\begin{tabular}{|c|c|c|c|c|c|}
\hline \multirow[b]{2}{*}{ Design factor/Kind } & & \multicolumn{2}{|c|}{ 2-row } & \multicolumn{2}{|c|}{ 3-row } \\
\hline & & $\begin{array}{l}\text { Existing } \\
\text { value }\end{array}$ & $\begin{array}{l}\text { Higher } \\
\text { speed } \\
\text { valuc }\end{array}$ & $\begin{array}{l}\text { Existing } \\
\text { value }\end{array}$ & $\begin{array}{c}\text { Higher } \\
\text { speed } \\
\text { value }\end{array}$ \\
\hline Rotational speed of threshing drum & $R(\mathrm{rpm})$ & \multicolumn{4}{|c|}{480} \\
\hline Diameter of threshing drum & $D(\mathrm{~cm})$ & \multicolumn{4}{|c|}{42} \\
\hline Distance belween plant bushes & $D_{n}(\mathrm{~cm})$ & \multicolumn{4}{|c|}{15} \\
\hline Cross-sectional area of each plant bushes & $A,\left(\mathrm{~cm}^{*}\right)$ & \multicolumn{4}{|c|}{$4 \pi$} \\
\hline Number of arrangement lines & $N$ & \multicolumn{4}{|c|}{4} \\
\hline Distance between impact lines & $D_{1}(\mathrm{~cm})$ & \multicolumn{4}{|c|}{12} \\
\hline Forward speed & $V_{s}(\mathrm{~cm} / \mathrm{s})$ & 60 & 90 & 80 & 100 \\
\hline \multicolumn{6}{|l|}{ Ratio of approaching speed of arrangement } \\
\hline line to the speed of feed chain & $R_{i}$ & 10.8 & 8.0 & 6.3 & 6.0 \\
\hline Number of imipact. & $N_{i}$ & 16 & 14 & 11 & 11 \\
\hline Thickness of feeding stem & $D_{b}(\mathrm{~cm} / \mathrm{s})$ & 3.9 & 4.5 & 4.5 & 5.5 \\
\hline
\end{tabular}

speed to get more capacity of threshing. Such design to speed up the threshing unit will need to make it clear to optimize main variables from simulation of varying variables involved. Here we simulated applying data of main variables given from the Table 3 and showed the results in the Fig. 4. 


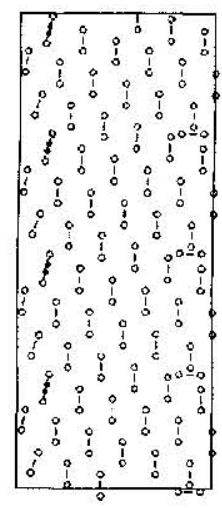

2-row combine

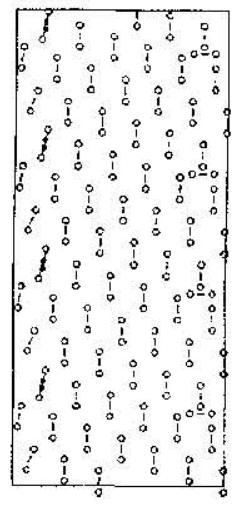

(b) 3-row combine

Fig. 4. Threshing teeth arrangement, designed for higher forward speed

\section{RESULTS AND CONCLUSIONS}

The objective of this study is to develop a design theory for the threshing unit that can adopt the changes of working capacity due to the increment of cutting rows and/or forward speed. The main design factors of the threshing unit considered in this study were the number of threshing teeth, the approaching angle of the teeth, the distance between teeth on arrangement line, the speed of feed chain, the number of arrangement Ines, and the total number of teeth.

'The computer simulation program was developed to design threshing drum and to arrange threshing teeth by applying the developed equations. The design simulation showed that the design method developed here went along well with the design of existing combines, and thus the method could be used for developing a new design of head-feeding combine having a varied capacity.

\section{REFERENCES}

Carrol, T. 1961. Combines. Agr. Eng. Handbook: 238-250

C. J. Chung, J. S. Choe, W. S. Lee, S. I. Chung 1992. Development of Design Theory on the Tooth Arrangement of the Combine Threshing Drum. Journal of the Korean Society for Agricultural Machinery 17(2): 171-176

C. J. Chung and S. I. Vam 1985. A Mathematical Model of Threshing Process of the Head-led Type Combine. Journal of the Korean Society for Agricultural Machinery 10(2): 36-46

Ezaki, H. 1972. Experimental stusies on promotion of capacity for head feeding type combine. IAM, Japan: 1-12

Quick, G. R. 1972. Plot combine development. Arg. Eng. (4): 49-50 